\title{
The Hypotensive Effect of Homoeopathic Medicines in the Management of the Patients Suffering From Uncomplicated Essential Hypertension - A Prospective, Observational Study
}

\author{
Dr.Nishant Daryani MD(Hom.) ${ }^{* 1}$ Prof. (Dr.) Nivedita Pattanaik MD(Hom.)**2 \\ ${ }^{I}$ Cosultant Homoeopath, Jaipur, (Raj.) \\ ${ }^{2}$ Deptt. of Homoeopathic Materia Medica\& Medical Supdt. of R. V. Homoeopathic Medical College \& Hospital, \\ Udaipur, (Raj.)
}

\begin{abstract}
:
Background: The World Health Organization (WHO) considersHypertension (HT) as one of the most important causes of premature death worldwide.It is directly responsible for $57 \%$ of all deaths due to stroke and $24 \%$ of all deaths due to coronary heart disease deaths in India. Recent studies conducted on Indian population have shown that the prevalence of hypertension in urban areas is $25 \%$, whereas, it is $10 \%$ in rural areas. ${ }^{1}$

According to the statistics of the WHO, homoeopathy is the second most useful health care system in the world. However, a meta-analysis in 2005 concluded that the clinical effects of homoeopathy are nothing but placebo effects. ${ }^{2}$ Although a conflicting conclusion was arrived at earlier in 1997 by another meta-analysis. ${ }^{3}$

The aim of this study was to evaluate whether individualized homoeopathic medicines could produce any significant hypotensive effect different from placebo in patients with essential hypertension by comparing the lowering of blood pressure level between groups.

Settings and Design: A prospective, double-blind, randomized, placebo-controlled, parallel-arm clinical trial was conducted atDr.NishantDaryani's clinic, Jaipur \&Dr.NiveditaPattanaik'sclinic, Udaipur.(Raj.).

Material and Methods:Total 233 hypertensive patients were assessed for eligibility, out of which 150 were enrolled and randomized for the study (verum/homoeopathy 70 \&control/placebo 80). Among 150 patients 18 were dropped out during the study while 132 remained under regular follow up (verum 64, control 68). The outcome measures were assessed at the end of 3 and 6 months.

Results: The baseline data were not significantly different between the groups. After 6 months, mean Systolic Blood Pressure (SBP) in the homoeopathy group reduction was $26.6 \mathrm{~mm} \mathrm{Hg}(95 \%$ CI 21.5, 31.7) whereasSBP in the placebo group increased by $3.6 \mathrm{~mm} \mathrm{Hg}$ (95\% CI -8.7, 1.5). Similarly, the mean Diastolic Blood Pressure (DBP) in the homoeopathy group reduced by $11.8 \mathrm{~mm} \mathrm{Hg}(95 \%$ CI 9.2, 14.4) whereas DBP increased by 1.6 $\mathrm{mm} \mathrm{Hg}(95 \% \mathrm{CI}-3.6,0.4)$ in the placebo group. Repeated measures ANOVA also showed significant difference $(P=0.0001)$ between the groups.

Detailed case recording of each patient was doneon Case recording format (CRF) following guidelines laid down by Master Hahnemann in Organon of Medicine ${ }^{4}$ and Kent's philosophy. Wherever required repertorization was done from synthesis repertory using RADAR software version $10.5^{6}$ and final selection of medicine was done through Homoeopathic MateriaMedica. Frequently prescribed medicines were Natrummur.,Lachesis, Glonoine, Gelsemium, Bryonia alba, Aurum met.,Pulsatilla, Sulphur, Digitalis and Belladonna.
\end{abstract}

Conclusion: Individualized homoeopathic medicines produced a significant hypotensive effect comparing to placebo.

Keywords: CI - Confidence Interval, Diastolic blood pressure,Essential hypertension, Homoeopathy, Placebo,Randomized controlled trial, Systolic blood pressure.

\section{Introduction}

Hypertension(HTN or HT) is classified intoPrimary or essential hypertension and Secondary hypertension. About $90-95 \%$ of cases are categorized as primary hypertension, defined as high blood pressure without any underlying cause. The remaining $5-10 \%$ of cases are categorized as secondary hypertension, defined as hypertension due to some identifiable cause, such as chronic kidney disease, narrowing of the aorta or kidney arteries, or an endocrine disorder such as excess aldosterone, cortisol, or catecholamines etc. ${ }^{1}$

Essential hypertension (primary hypertension or idiopathic hypertension) the most common type of hypertension, tends to be familial in origin and is likely to be the consequence of an interactionbetween environmentalandgeneticfactors.Prevalence of essential hypertension increases with age, and individuals with relatively high blood pressure at younger ages are at higher risk for the subsequent development of hypertension. Hypertension can increase the risk of cerebral, cardiac, and renal events. ${ }^{7}$ 
Dietary and lifestyle modification can improve blood pressure control and decrease the risk of health complications, although treatment with medication is required in cases where patient`s lifestyle changes are not enough or not effective.

\section{Aims \&Objectives}

To evaluate whether individualized homoeopathic medicines can produce any significant effect different from placebo in uncomplicated essential hypertension by comparing the lowering of blood pressure between groups.

\section{Study Setting and Design -}

\section{Material And Methods}

The present study was a prospective, double-blind, randomized, placebo-controlled, parallel-arm trial, conducted at Dr.NishantDaryani's clinic, Jaipur \&Dr.NiveditaPattanaik'sclinic, Udaipur. (Raj.)between January 2015 to June 2015, as per the Reporting Data on Homoeopathy Treatment's (ReDHoT) guidelines. ${ }^{8}$

Screening and enrollment was followed by intervention and follow-up for next 6 months[Figure 1]. The study protocol was completely in accordance with the Helsinki declaration on human experimentation and Good Clinical Practice. ${ }^{9}$

Figure 1: Consort Study Flow Diagram

HYPERTENSIVE PATIENTS ASSESED ELIGIBILITY

$(n=233)$

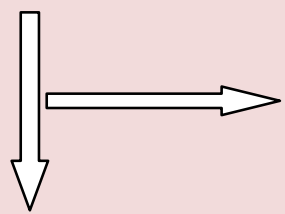

RANDMIZED $(n=150)$

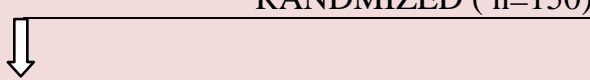

Allocated Homoeopathy $(\mathrm{n}=70)$<smiles>[CH]=C</smiles>

Dropped out $(n=6)$<smiles>[CH]=C</smiles>

Analyzed ( $n=64)$
EXCLUDED $(\mathrm{n}=83)$

1. Malignant HT.( 5)

2. Isolated HT. (2)

3. Antihypertensive

Therapy ( 56)

4. Severe Concomitant

Disease ( 3)

5. Pregnancy (4)

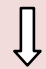

Allocated Placebo $(n=80)$<smiles>[CH]=C</smiles>

Dropped out $(n=12)$<smiles>[CH]=C</smiles>

Analyzed $(\mathrm{n}=68)$

Table 1: Baseline data $(n=150)$

\begin{tabular}{|c|c|c|c|}
\hline & \multicolumn{2}{|c|}{ BASE LINE DEMOGRAPHIC DATA } & \multirow[b]{2}{*}{ P VALUE } \\
\hline $\begin{array}{l}\text { SOCIO DEMOGRAPHIC } \\
\text { CHARECTERISTIC }\end{array}$ & $\begin{array}{l}\text { HOMOEOPATHY } \\
(\mathbf{n}=70)\end{array}$ & $\begin{array}{c}\text { PLACEBO } \\
(\mathbf{n}=\mathbf{8 0})\end{array}$ & \\
\hline \multicolumn{4}{|l|}{ AGE } \\
\hline 20- 35 YEARS & $(7.14 \%)$ & $(11.25 \%)$ & 0.561 \\
\hline 36 - 50 YEARS & $(38.57 \%)$ & $28(35 \%)$ & 0.777 \\
\hline $51-65$ YEARS & $38(54.29 \%)$ & $43 \quad(53.75 \%)$ & 0.922 \\
\hline \multicolumn{4}{|l|}{ GENDER } \\
\hline MALE & $27(38.57 \%)$ & $31 \quad(38.75 \%)$ & 0.884 \\
\hline FEMALE & $43(61.43 \%)$ & $49 \quad(61.25 \%)$ & 0.884 \\
\hline F/H OF HT & $25(35.71 \%)$ & $29 \quad(36.25 \%)$ & 0.919 \\
\hline \multicolumn{4}{|l|}{ MARITAL STATUS } \\
\hline MARRIED & $61(87.14 \%)$ & $65(81.25 \%)$ & 0.448 \\
\hline UNMARRIED & $9(12.86 \%)$ & $15(18.75 \%)$ & 0.448 \\
\hline HABITATE & & & \\
\hline
\end{tabular}


The Hypotensive Effect of Homoeopathic Medicines In The Management ofthe Patients...

\begin{tabular}{|c|c|c|c|}
\hline URBAN & $56(80 \%)$ & $64(80 \%)$ & 0.838 \\
\hline RURAL & $14(20 \%)$ & $16(20 \%)$ & 0.838 \\
\hline RISK FACTORS & & & 0.919 \\
\hline STRESS & $45(64.29 \%)$ & $51(63.75 \%)$ & 0.939 \\
\hline SEDENTARY HABIT & $32(45.71 \%)$ & $36(45 \%)$ & 0.575 \\
\hline RICH FOOD & $37(52.86 \%)$ & $47(58.75 \%)$ & 0.732 \\
\hline HIGH SALT INTAKE & $50(71.43 \%)$ & $54(67.5 \%)$ & 0.878 \\
\hline SMOKING & $21(30 \%)$ & $26(32.5 \%)$ & 0.723 \\
\hline
\end{tabular}

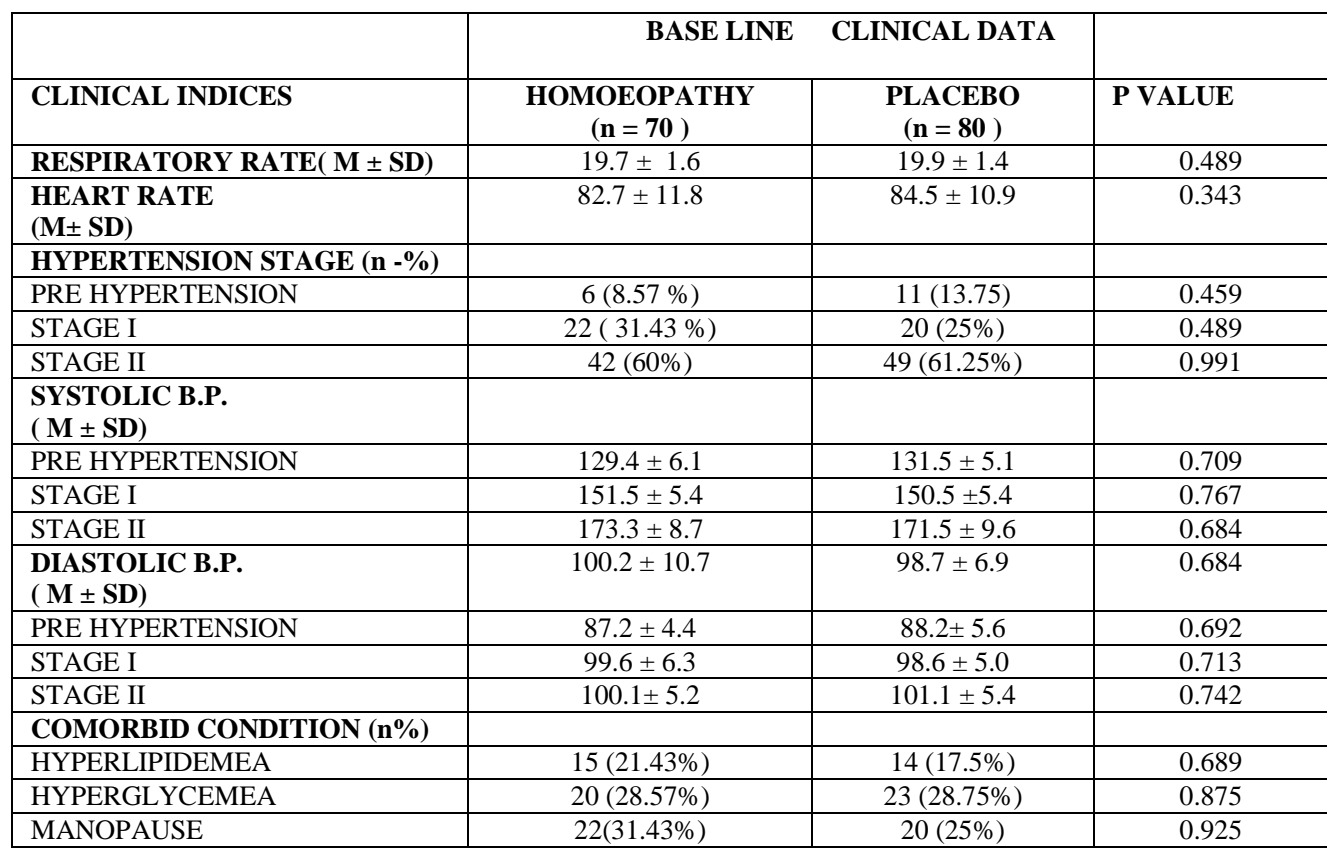

\begin{tabular}{|c|c|c|c|}
\hline & \multicolumn{2}{|c|}{$\begin{array}{c}\text { BASELINE PATHOLOGICAL } \\
\text { BIOCHEMICAL DATA }\end{array}$} & \multirow[b]{2}{*}{ P VALUE } \\
\hline INDICES & $\begin{array}{l}\text { HOMOEOPATHY } \\
(\mathrm{n}=70)\end{array}$ & $\begin{array}{l}\text { PLACEBO } \\
(\mathbf{n}=\mathbf{8 0})\end{array}$ & \\
\hline \multicolumn{4}{|l|}{$\begin{array}{l}\text { BLOOD SUGAR : } \\
(M \pm \text { SD })\end{array}$} \\
\hline FASTING & $105.8 \pm 29.2$ & $107.1 \pm 27.3$ & 0.284 \\
\hline POST PANDRIAL -1 hour & $141.2 \pm 28.1$ & $140.4 \pm 40.5$ & 0.436 \\
\hline $\begin{array}{l}\text { BLOOD UREA: } \\
(\mathrm{M} \pm \text { SD })\end{array}$ & $28.6 \pm 9.8$ & $29.1 \pm 8.9$ & 0.192 \\
\hline $\begin{array}{l}\text { S. CREATININE: } \\
(\mathrm{M} \pm \mathrm{SD})\end{array}$ & $0.9 \pm 0.2$ & $0.8 \pm 0.1$ & 0.490 \\
\hline \multicolumn{4}{|l|}{$\begin{array}{l}\text { LIPID PROFILE : } \\
(M \pm \text { SD })\end{array}$} \\
\hline TOTAL CHOLESTEROL & $222.7 \pm 28.1$ & $219.2 \pm 32.5$ & 0.107 \\
\hline HDLC & $46.9 \pm 8.1$ & $47.1 \pm 6.1$ & 0.176 \\
\hline LDLC & $141.7 \pm 21.8$ & $138.2 \pm 22.7$ & 0.108 \\
\hline VLDLC & $32.8 \pm 12.9$ & $32.5 \pm 11.6$ & 0.362 \\
\hline TRIGLYCERIDE & $195.0 \pm 65.4$ & $202.7 \pm 75.5$ & 0.227 \\
\hline \multicolumn{4}{|l|}{ URINE MICROSCOPIC: $\mathbf{n} \%$} \\
\hline ALBUMINUREA (TRACE) & $4(5.71 \%)$ & $5(6.21 \%)$ & 1.000 \\
\hline PUS CELL (10-20)/ FLD & $3(4.29 \%)$ & $3(3.75 \%)$ & 1.000 \\
\hline
\end{tabular}

[ Chi-square \& independent $\mathrm{t}$ test were applied, Fisher's exact $\mathrm{P}$ value, ${ }^{*} \mathrm{P}<0.05$, two tailed considered as statistically significant. ECG, HDLC, LDLC, VLDC.]

\section{Patient selection -}

Inclusion criteria : The study inclusion criteria consisted of patients: (1) suffering from essential hypertension (pre-hypertensives: SBP 120-139 mm Hg, DBP 80-89 mm Hg; Stage I hypertensives: SBP 140$159 \mathrm{~mm} \mathrm{Hg}$, DBP 90-99 mm Hg; and Stage II hypertensives: SBP $\geq 160 \mathrm{~mm} \mathrm{Hg}$, DBP $\geq 100 \mathrm{~mm} \mathrm{Hg}$; (2) between 20-65 years of age; (3) of both sexes; (4) having at least six-month history of suffering; (5) history, 
examination, and routine investigations did not revealed any complications or secondary causes; and (6) given written informed consent.

Exclusion criteria : Cases were considered excluded where : (1) diagnosis or findings from the history were uncertain; (2) physical examination or routine investigations produced suspicion of a secondary cause for hypertension; (3) diagnosed (provisional/confirmatory) cases of secondary hypertension; (4) any kind of continued anti-hypertensive therapy in last six months; (5) cases of malignant hypertension (SBP >200 mm Hg and DBP >140 mm Hg) with clinical features of hypertensive encephalopathy (severe headache, vomiting, visual disturbances, transient paralysis, convulsion, stupor and coma), cardiac decompensation (heart failure), and rapidly declining renal function (oliguria); (6) patients suffering from isolated systolic hypertension (SBP $\geq 140 \mathrm{~mm} \mathrm{Hg}$ and/or $\mathrm{DB} P<90 \mathrm{~mm} \mathrm{Hg}$ ), as was mostly found in elderly patients;(7) patients with labile (sometimes, but not always, arterial pressure in the hypertensive range, i.e. not sustained) hypertension; (8) patients not strictly conforming to the criteria given by the Joint National Committee - 7 (although variation of \pm $10 \mathrm{~mm} \mathrm{Hg}$ in SBP and/or DBP was considered); (9) presence of severe concomitant disease (s); (10) complications with HT i.e. failure of vital organs/systems, for example, kidney, heart, liver, lungs and the like, as detected clinically; (11)presence of any systemic affections (endocrinal/cardiovascular/locomotor/neurological/ hematological/ psychiatric etc.) or infectious disease(s) that were already diagnosed or detected clinically or in routine labinvestigations; (12) immune compromised patients; (13) diagnosed cases of developmental defects or congenital abnormalities; (14) pregnant and lactating mothers; and (15) patients with a history of drug and/or alcohol abuse.

\section{Intervention (Homoeopathic Medicine) /Comparator (Placebo):}

A range of homoeopathic medicines with their potencies in centesimal scale were used as per the requirement of the case, decided by the treating physicians. All the medicines used were manufactured by SBL Company of India.

Medicines and placebo were dispensed in Good Clinical Practice environment. Each dose of either medicine or placebo, administered orally, 4 pills at a time, identical in appearance, i.e. medicated with 30 numberglobules.

\section{Sample size:}

The hypertensive status of the study population was initially confirmed by taking the average of the measured blood pressure twice on two separate occasions in both arms in a supine position during rest, using a mercury sphygmomanometer of standard cuff size; the same was repeated throughout the study. Every case was subjected to detailed screening by a specified eligibility criteria followed by recruitment in the trial. After recruitment, all patients were subjected to baseline assessments. The pre-entry and post-intervention laboratory investigations performed were as follows: Blood for routine investigation (CBC, ESR - $1^{\text {st }}$ hour, FBS, PPBS2hrs., urea, creatinine, Lipid Profile), urine analysis (albumin, RBC, WBC or pus cells), chest X-ray PA- view, and ECG were performed before and after an intervention of 6 months.

Data were extracted from the reports directly and independently. Pre-designed case recording format (CRF) was used by the investigators. All these were compiled at the end \& data were extracted and analyzed. Out of 233 hypertensive patients assessed for the eligibility criteria, 150 were enrolled. Then individual treatment was prescribed to all the enrolled participants. The treating physicians were free to decide the homoeopathic medicines, dosage and repetitions to be applied.

The patients were allocated randomly into one of the intervention groups with the help of coin-toss method. Randomization codes ('h' = heads, ' $t$ ' = tail) were mentioned on the prescription of each participant by the treating physicians and were sent to the pharmacist. The pharmacist was instructed to serve to the groups as per the mentioned codes on the prescription. The treating physicians were kept blinded from the code of allocation, in strict confidentiality, throughout the study. The codes were decoded after the end of the trial. Thus, 70 participants were found to be randomized to verum (homoeopathy) and 80 to control (placebo). A total of 18 cases were dropped out (verum 6, placebo 12)while 132 remained under regular follow-up (verum 64, placebo 68).

If necessary, the prescription was changed in the course of time, and of course, the patients who started on placebo stayed on placebo, except during intercurrent acute illness.

A detailed case recording of each patient was done by the investigators on CRF as per the guidelines laid down by Hahnemann in Organon of Medicine ${ }^{4}$ and Kent's philosophy; ${ }^{5}$ Repertorization was done on the basis of the totality of symptoms fromsynthesis repertory using RADAR software version $10.5^{6}$ and final selection of medicine was done through Homoeopathic MateriaMedica. In either group, patients were followed up in person on every $14^{\text {th }}$ day and finally at the end of $6^{\text {th }}$ month, by measurement of blood pressure.

During the six-month trial, all data were measured and analyzed at entry, after three months, and after six months of the study by the outcome assessor. 


\section{Results}

Out of 233 hypertensive subjects assessed for the eligibility criteria, 83 were excluded and remaining 150 were randomized into two groups, in which 70 patients were allocated to verum (homoeopathy) and 80 to placebo group (control).

Among total 150 selected patients 18 were dropped out during the study (verum 6; placebo12). In this way 64 participants out of 70 from verum, and 68 out of 80 participants from placebo group were included in the final analysis. In the verum group, 2 subjects withdrew themselves from the study, 3 failed to continue regular follow-up for the minimum required duration or investigations for the conduct of analysis, and 1 developed hepatitis during the course of study and attended other treatment. In the placebo group, 8 subjects withdrew themselves; 3 were irregular, and 1 needed active therapeutic intervention for sudden deterioration of condition [Figure 1].

After 6 months of intervention, change in blood pressure showed a statistically significant trend in favor of homoeopathy. Blood pressure was lowered significantly in $54(84.4 \%)$ and 9 pts.(13.2\%) in the verum and placebo groups respectively, $\left(\chi_{1}{ }^{2}=64.06 ; \mathrm{P}=0.000\right.$, two-tailed). BP remained unimproved (static or deteriorated) in $10(15.63 \%)$ patients in the verum group and $59(86.76 \%)$ patients in the placebo group.

After 3 months, mean SBP and DBP reduction was 16.6 (95\% CI 9.9, 23.3) and 7.3 (95\% CI 4.1, 10.5) $\mathrm{mm} \mathrm{Hg}$ respectively in the verum (homoeopathy) group. Contrarily, mean SBP and DBP raised by 2.2 (95\% CI $-7.2,2.8)$ and $1.6(-3.6,0.4) \mathrm{mm} \mathrm{Hg}$ respectively in the placebo group.

Again after 6 months, mean SBP and DBP reduction was 26.6 (95\% CI 21.5, 31.7) and 11.8 (95\% CI $9.2,14.4) \mathrm{mm} \mathrm{Hg}$ respectively in theverum(homoeopathy) group. The mean SBP and DBP increased by 3.6 $(95 \% \mathrm{CI}-8.7,1.5)$ and $1.6(-3.6,0.4) \mathrm{mm} \mathrm{Hg}$ respectively in the placebo group.

Repeated measures ANOVA was performed comparing data obtained at baseline, at 3 months and 6 months, which also revealed significant difference between the two groups, both in SBP[F=77.2]; $\mathrm{P}=0.0001$ and $\mathrm{DBP}[\mathrm{F}=63.2] ; \mathrm{P}=0.0001$.

Post hoc independent $t$ test was carried out comparing 3 months and 6 months values which showed a statistically significant difference between groups, both in SBP (mean difference $=-17.8, t=-6.2$ and mean difference $=-29.2, t=-10.38, P=0.001)$ after 3 months and 6 months respectively and DBP $($ mean difference $=$ $-7.4, t=-6.1$ and mean difference $=-11.8, t=-11.47 ; P=0.001$ ) after 3 and 6 months respectively. ([Figure 2], [Table 2])

Figure 2: Mean changes of Blood Pressure over time

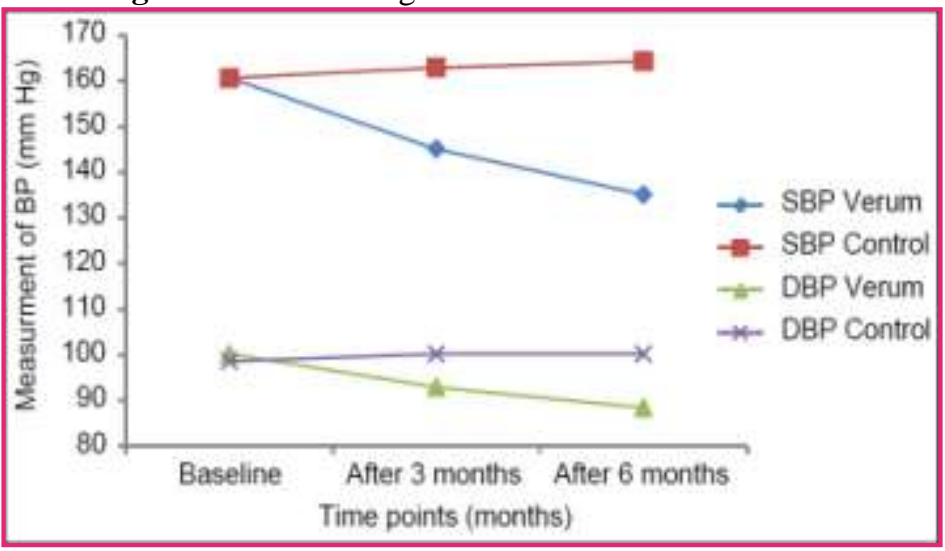

Table 2:

Blood Pressure changes in the two groups over different points in time

\begin{tabular}{|c|c|c|c|c|c|c|c|}
\hline GROUPS & \multicolumn{3}{|c|}{ SBP $($ mean \pm SD $)$} & \multicolumn{2}{|c|}{ WITHIN Gr. } & \multicolumn{2}{|c|}{ BETWEEN Gr. } \\
\hline & Baseline & At $3^{\text {rd }}$ months & At $6^{\text {th }}$ months & F value & $\begin{array}{l}\mathbf{P} \\
\text { value }\end{array}$ & F value & $\begin{array}{l}\mathbf{P} \\
\text { value }\end{array}$ \\
\hline $\begin{array}{l}\text { HOMOEOPATHY } \\
(n=70)\end{array}$ & $161.7 \pm 21.3$ & $145.1 \pm \mathbf{1 9 . 0}$ & $135.1 \pm \mathbf{1 8 . 3}$ & 71.90 & 0.0001 & 77.2 & $\begin{array}{c}0.000 \\
1\end{array}$ \\
\hline $\operatorname{PLACEBO}(n=80)$ & $160.7 \pm 16.9$ & $162.9 \pm \mathbf{1 5 . 3}$ & $164.3 \pm \mathbf{1 5 . 8}$ & 7.50 & 0.001 & - & - \\
\hline P value & NS & 0.001 & 0.001 & & & & \\
\hline GROUPS & \multicolumn{3}{|c|}{ DBP $($ mean \pm SD $)$} & \multicolumn{2}{|c|}{ WITHIN Gr. } & \multicolumn{2}{|c|}{ BETWEEN Gr. } \\
\hline & Baseline & At $3^{\text {rd }}$ months & At $6^{\text {th }}$ months & F value & P value & F value & $\mathbf{P}$ \\
\hline
\end{tabular}


The Hypotensive Effect of Homoeopathic Medicines In The Management ofthe Patients...

\begin{tabular}{|l|l|l|l|l|l|l|l|}
\hline & & & & & & value \\
\hline $\begin{array}{l}\text { HOMOEOPATHY } \\
(\mathbf{n}=\mathbf{7 0})\end{array}$ & $100.2 \pm \mathbf{1 0 . 7}$ & $92.8 \pm \mathbf{8 . 5}$ & $88.3 \pm \mathbf{6 . 7}$ & 57.62 & 0.001 & 63.2 & 0.000 \\
\hline PLACEBO(n= 80) & $98.6 \pm \mathbf{6 . 8}$ & $100.1 \pm$ & & & & & \\
\hline P value & NS & 0.001 & 0.001 & & & & \\
\hline
\end{tabular}

An unpaired/independent $t$ test was carried out comparing three months and six months values showed a statistically significant difference between groups, both in SBP $(t=-6.261$ and -10.386 after three and six months respectively; $P=0.001$ two-tailed) and DBP $(t=-5.966$ and $-11.452 ; P=0.001$ two-tailed $)$. [Table 2]; [Figure 2]

The most frequently prescribed homoeopathic medicines and placebo respectively in both groups were Natrummuriaticum $(n=19,19)$, Lachesis $(n=11,11)$, Glonoine $(n=10,11)$, Gelsimium $(n=7,7)$, Bryonia alb. $(n=4,6)$, Aurum met $(n=4,5)$, Pulsatilla $(n=3,3)$,Sulphur $(n=2,2)$, Digitalis $(n=2,2)$, and Belladonna $(n=2$, 2) in varied potencies [Table 3$]$.

Table 3: Most Often Prescribed Homoeopathic Medicines

\begin{tabular}{|c|c|c|c|}
\hline Medicine & $\begin{array}{c}\text { Homoeopathy } \\
\text { Number of Prescriptions }\end{array}$ & $\begin{array}{c}\text { Placebo } \\
\text { Number of } \\
\text { Prescriptions }\end{array}$ & P Value \\
\hline Natrummur & 19 & 19 & 0.639 \\
\hline Lachesis & 11 & 11 & 0.936 \\
\hline Glonoine & 10 & 11 & 0.959 \\
\hline Gelsimium & 7 & 7 & 0.985 \\
\hline Bryonia alba. & 4 & 6 & $1.000^{(\dagger)}$ \\
\hline Aurum met. & 4 & 5 & $1.000^{(\dagger)}$ \\
\hline Pulsatilla & 3 & 3 & $1.000^{(\dagger)}$ \\
\hline Sulphur & 2 & 2 & $1.000^{(\dagger)}$ \\
\hline Digitalis & 2 & 2 & $1.000^{(\dagger)}$ \\
\hline Belladonna & 2 & 2 & \\
\hline
\end{tabular}

[ Chi-square test; $P$ value two tailed at $95 \% \mathrm{Cl}$; ${ }^{\dagger}$ Fisher`s exact $P$ value; $P<0.05$ considered as statistically significant ]

Table 4: After Six Months Change In Blood Pressure

\begin{tabular}{|c|c|c|c|c|c|c|}
\hline \multirow{2}{*}{} & \multicolumn{3}{|c|}{ Homoeopathic Group } & \multicolumn{3}{c|}{ Placebo Group } \\
\hline Medicine & $\begin{array}{c}\text { Number of } \\
\text { Prescriptions }\end{array}$ & $\begin{array}{c}\text { Effect } \\
\text { in Nos. }\end{array}$ & IN \% & $\begin{array}{c}\text { Number of } \\
\text { Prescriptions }\end{array}$ & $\begin{array}{c}\text { Effect } \\
\text { in Nos. }\end{array}$ & IN \% \\
\hline Natrummur & 19 & 17 & 89.4 & 19 & 3 & 15.7 \\
\hline Lachesis & 11 & 10 & 90.9 & 11 & 1 & 9 \\
\hline Glonoine & 10 & 9 & 90 & 11 & 2 & 18.1 \\
\hline Gelsimium & 7 & 5 & 71.4 & 7 & 1 & 14.2 \\
\hline Bryonia alba. & 4 & 4 & 100 & 6 & 1 & 16.6 \\
\hline Aurum met & 4 & 3 & 75 & 5 & 0 & 00 \\
\hline Pulsatilla & 3 & 2 & 66.6 & 3 & 1 & 33.3 \\
\hline Sulphur & 2 & 2 & 100 & 2 & 0 & 00 \\
\hline Digitalis & 2 & 1 & 50 & 2 & 0 & 00 \\
\hline Belladonna & 2 & 1 & 50 & 2 & 0 & 00 \\
\hline TOTAL & 64 & 54 & 84.4 & 68 & 9 & 13.2 \\
\hline
\end{tabular}

\section{Discussion}

Individualized homoeopathic medicines definitely produced some hypotensive effects different from placebo. Homoeopathic prescriptions in our study were based on homoeopathic principles. Mild-to-moderate hypertension in many cases is asymptomatic, emphasizing the need for a holistic approach.

The final differentiation of the medicines was done with the help of Homoeopathic MateriaMedica;frequently prescribed medicines wereNat.mur., Lachesis, Glonoine, Gelsimium, Bryonia alb., Arum met., Pulsatilla, Sulphur, Digitalis and Belladonna. The medicines were selected following the principles of homoeopathy and were never be used specifically or blindly to control hypertension.

During the follow-up visits, repetition was done as per the requirement of the case following Homoeopathic principles.

There are numerous arguments in the medical literature as to whether Homoeopathic medicines are mere placebo or not. Homoeopaths feel that the way modern medicine looks at drug trial is not conductive in measuring positive homoeopathic effects because different patients with same disease and disease complications may need different individualized medicine rather than giving the same treatment for all patients with similar disease as in modern medicine. 
The limitation of the study was that we excluded patients having malignant hypertension or having any complication, hence, the study is unable to answer the question as to whether homoeopathy will be equally useful in patient with malignant hypertension or having complications with it.

The present trial, although small shows the positive effect of homoeopathic medicines. Since this was only twocenters study. Question about its generalizability arises, a multicentric double blind randomized study using homoeopathic medicine is required in future.

\section{Conclusion}

Finally our data suggest that individualized homoeopathic treatment have significantly beneficial effects different from placebo in patients suffering from uncomplicated essential hypertension. It may be adopted as an alternative public health approach in curbing the increasing prevalence of hypertension throughout the globe.

\section{Reference}

[1] Hypertension [ Internet]. [Updated 2015 September 22 ; cited on 2015 September 29]. Available from: https://en.wikipedia.org/wiki/Hypertension

[2] Shang A1, Huwiler-Müntener K, Nartey L, Jüni P, Dörig S, Sterne JA, Pewsner D, Egger M. Are the clinical effects of homoeopathy placebo effects? Comparative study of placebo-controlled trials of homoeopathy and allopathy. Lancet.[ Internet]. 2005 Aug 27-Sep 2; 366(9487):726-32. [cited on 2015 September 29]. Available from: http://www.ncbi.nlm.nih.gov/pubmed/16125589

[3] Linde K1, Clausius N, Ramirez G, Melchart D, Eitel F, Hedges LV, Jonas WB. Are the clinical effects of homeopathy placebo effects? A meta-analysis of placebo-controlled trials. Lancet. [Internet]. 1997 Sep 20;350(9081):834-43. [cited on 2015 September 29]. Available from: http://www.ncbi.nlm.nih.gov/pubmed/9310601.

[4] Hahnemann Samuel. Organon of Medicine. Fifth \&Sixth Edition (Eighth Indian Edition). Calcutta: M. Bhattacharya \& Co.(P)Ltd. 1984.

[5] Kent James Tylor. Lectures on Homoeopathic Philosophy. New Delhi: B. Jain Publishers (P) Ltd. 1993.

[6] SchroyensFrederik. Synthesis from RADAR SOFTWARE [version 10.5]

[7] Essential hypertension. [Internet]. 2015 August 31st. [cited on 2015 September 29]. Available from: https://en.wikipedia.org/wiki/Essential_hypertension

[8] Dean ME1, Coulter MK, Fisher P, Jobst KA, Walach H. Reporting data on homeopathic treatments (Re d Hot): a supplement to CONSORT. J Altern Complement Med. [Internet]. 2007 Jan-Feb;13(1):19-23. [citedon 2015 September 29]. Available from:http://www.ncbi.nlm.nih.gov/pubmed/17309373

[9] World Medical Association Declaration of Helsinki Ethical Principles for Medical Research Involving Human Subjects.The Journal of the American Medical Association.[Internet]. 2013 November 27, Vol. 310, No. 20. [citedon 2015 September 29]. Available from:http://jama.jamanetwork.com/article.aspx?articleid=1760318 